\title{
Planetary-Scale RFID Services in an Age of Uberveillance
}

\author{
This paper discusses possible futures for RFID, including an alternative \\ to bar code tagging, and outlines a vision of a future RFID \\ product service system.
}

By Katina Michael, Senior Member IEeE, George Roussos, Member IEeE, George Q. Huang, Arunabh Chattopadhyay, Rajit Gadh, Member IEeE, B. S. Prabhu, and Peter Chu

\begin{abstract}
Radio-frequency identification (RFID) has a great number of unfulfilled prospects. Part of the problem until now has been the value proposition behind the technology - it has been marketed as a replacement technique for the barcode when the reality is that it has far greater capability than simply non-line-of-sight identification, towards decision making in strategic management and reengineered business processes. The vision of the internet of things (IOT) has not eventuated but a world in which every object you can see around you carries the possibility of being connected to the internet is still within the realm of possibility. However incremental innovations may see RFID being sold as a service (much like photocopiers are maintained today) than a suite of technologies within a system that are sold as individual or bundled packaged components. This paper outlines the vision for such a product service system, what kinds of smart applications we are likely to see in the future as a result, and the importance of data management capabilities in planetary-scale systems.
\end{abstract}

KEYWORDS | Innovation; radio-frequency identification (RFID); service; vision

Manuscript received April 16, 2010; revised May 9, 2010; accepted May 12, 2010. Date of publication July 15, 2010; date of current version August 20, 2010.

K. Michael is with the Centre for Business Services Science, University of Wollongong Wollongong, N.S.W. 2522, Australia (e-mail: katina@uow.edu.au).

G. Roussos is with the Department of Computer Science and Information Systems, Birbeck College, University of London, London WC1E 7HX, U.K. (e-mail: g.roussos@birkbeck.ac.uk).

G. Q. Huang is with the Department of Industrial and Manufacturing Systems Engineering, The University of Hong Kong, Hong Kong (e-mail: gqhuang@hku.hk). A. Chattopadhyay, R. Gadh, B. S. Prabhu, and P. Chu are with the Wireless Internet for the Mobile Enterprise Consortium (WINMEC), Henry Samueli School of Engineering and Applied Science, University of California Los Angeles,

Los Angeles, CA 90095 USA (e-mail: rgadh@winmec.ucla.edu; winmec@winmec.ucla.edu).

Digital Object Identifier: 10.1109/JPROC.2010.2050850

\section{INTRODUCTION}

Increasingly radio-frequency identification (RFID) will not be viewed as just another barcode-type technology. Instead it will be used in innovative ways for which it was never originally intended. While by its very nature RFID tells us "what is," industry has focused its attention on achieving adequate read rates using this non-line-of-sight technology, rather than on the value-added "where is," "when is," and in "what condition." Indeed, the value is not merely in identifying a product, but knowing where that product is, when it was last there, and in what condition it was when it was last sighted. To know the what, the where, the when, and the condition of an object or subject will one day grant the firm a type of divine omnipresent view (but not strictly speaking omniscient view) over its entire operations, an idea that has been explored by Michael and Michael and coined uberveillance [1]. With respect to the retail supply chain, for instance, uberveillance is the all pervasive ability to surveil an item or person handling an item, end-to-end, from the primary producer to the end user. The future of RFID is in managing visibility, managing velocity, and managing variability, giving organizations the kind of real-time data they (and their customers in particular) have craved for. It is the ability to be agile in decision making, responding to changes in the service economy.

\section{BACKGROUND}

The Auto-ID Centerhas long touted the vision of the internet of things (IOT). Brock [2] first used the term to imply an open platform for innovation but the vision of a "smart world" today remains an unfulfilled prophecy. Some have blamed this uneventful happening on the closed, proprietary, and somewhat exclusive system 
designed by the Auto-ID Center, pointing to technical barriers, while others have described governance-related barriers to participation. Whatever the reason for the shortcomings, we are left with a technology with great potential but unrealized capability. The International Telecommunication Union's (ITU) interpretation of the IOT is one that is more attractive and perhaps amenable [3]; a vision where almost every object you can see around you carries the possibility of being connected to the internet. This means that your domestic appliances, your clothes, your books, and your car may one day be assigned a unique IP address, just as both computers and web pages are assigned them today, to enable digital communications. Neither the original vision of the Auto-ID Center nor the vision of the more recently established EPCglobal has addressed the interactivity that occurs between nonliving things and living things, but it seems only logical that if we hope to enact revolutionary changes to business processes that this must be the next radical transformation in our corporate, community, and personal spheres. It is what has led the Auto-ID Labsto recant on their claim to the IOT concept toward a more plausible web of things (WOT) [4].

\section{A. Problems With RFID Adoption}

Potential benefits of adopting RFID in supply chain management (SCM) are widely recognized and reported. The actual benefits are yet to be achieved in RFID implementation as compared to the mandated milestones. Three hurdles dominate the delay. They are related to high levels of acquisition cost, risk, and specialist technical skills. First, specialist technical skills are required to manage the wide variety of RFID devices and tags with different frequencies and capacities, and their software application protocol interfaces (API) under varying application environments. Second, the rapid developments in RFID technologies and their fluctuating reading reliability have caused significant risks for real-life industrial implementations. Companies are worried about obsoleteness before they adopt solutions. Companies are also very much concerned about the customizability of the solutions they purchase to their specific and unique business conditions and operations. Third, despite all efforts made so far to reduce the costs of RFID devices and tags, as well as associated middleware and other software components, there is still a perception that RFID systems are too expensive for the enterprise to invest in to gain promised benefits. This is particularly true due to the lack of best practice guidelines for deploying these components.

\section{RFID AS A SERVICE}

Enter the ability to see every business process that happens in the world as a "service," and even more provocatively to claim that every product that is created should be considered a "service" [5]. The future of RFID will hinge on the successful cocreation of a service between stakeholders. This notion of cocreation does not claim, for instance, merely that one stakeholder is a participant in the creation of a service, but that they are part creators of a service, that they live and breathe it as if it were their own. This is the act of continually sharing sources of knowledge interactively and intimately between what was once considered disparate members of a single (albeit meshed) chain. Although intricate dependencies between members of any chain (supply or value) have been known to exist, cocreation is about oneness of mind through the feedback mechanism. It seems this is the only way in which RFID will really prosper and will be guided by robust design principles that are all-inclusive and shared between a set of stakeholders. And perhaps nontraditionally, this stakeholder set will be composed of more than just the firm and the customer; cocreation will require representatives from private and public organizations to serve holistic requirements in order to overcome cross-functional challenges. This goes beyond the concept of coproduction which emphasized the need for a firm and a customer to work together to produce an offering. Without cocreation, it is claimed that there can be no real value [6].

This new level of complexity encountered in cocreation is underpinned by theories in design science and innovation. In order to transform, or to make changes that are considered disruptive or even radical, existing ideas are brought together in new ways to satisfy the needs of all stakeholders. When ideas do not satisfy the desires of the firms, or add meaningful value, they are scrapped or individual stakeholders forgo representation. Social innovation, social entrepreneurship, and service innovation are terms that are used synonymously in the literature to describe this kind of activity. Highly successful ventures usually involve collaboration across sectors between companies, the nonprofit sector, and government. This establishes enough of a buy-in between stakeholders who are willing to collaborate openly to minimize the risk of failure in what some would consider the ambitious creation of a new service. Such thinking is characterized by organic growth and investment in research and development, not just on keeping things stable.

\section{THE PRODUCT SERVICE SYSTEM}

Currently, companies must take risks in investing in acquiring expensive RFID components and technical skills, whether using internal or external or joint project teams. This adoption mode may not be practical nor may it be necessary, especially to small and medium enterprise (SME). On the one hand, SMEs, individually, may not have the practical financial strengths to gain RFID benefits. On the other hand, SMEs are always associated with other SMEs or large corporations. For example, small and medium manufacturers and suppliers of automotive components may be physically located in an industrial park or region, operationally associated with their 
customers or business alliances. Such associations form a logical foundation for these SMEs to jointly solve problems to do with high acquisition costs, risk, and specialist technical skills. For example, they can share the specialist technical skills and middleware services, thus reducing the cost and risk. A new business model is therefore needed for RFID adoption.

The concept of the product service system (PSS) has been increasingly used as a new business model in implementing advanced technologies including RFID [7]. PSS, unlike the traditional model of focusing just on products, recognizes that services in combination with products are more likely to yield higher profits for the business. The adoption of PSS leads to significant change in the manner in which business is conducted in a value chain. The revenue of a manufacturer comes from the sale of providing product functionality while retaining the product ownership rather than from the sale of products. One of the most successful real-life examples of integrating services into products is that office users are renting photocopiers instead of buying them. The rental is charged on the utilization level (e.g., number of copies). Users are ensured to have the photocopying functionality during office hours through a guarantee of timely repairing and maintenance services from a service stakeholder in this PSS. As another example, Rolls-Royce (R-R) delivers power-by-the-hour instead of transferring ownership of the gas turbine engine to an airline company [7]. At the other end, an example of integrating products into services is that of mobile communication providers giving a free mobile phone handset to customers who sign up for a service. Another example is that internet service providers (ISPs) deploy connection facilities in hotels free of charge but share the revenue obtained from the residents' internet usage.

Following the PSS business model, the usage of automatic identification services is sold to end users while RFID solution providers retain the ownership of RFID devices, software, and networks. End users do not have to invest in acquiring RFID hardware devices that are not charged by ownership but usage. RFID manufacturers share and reduce technical risks and total costs with end users by retaining the ownership and by providing upgrades to their devices. In addition, RFID solution providers are responsible for technical support for RFID systems throughout the implementation process. Such support is shared among multiple end users, leading to further reduction in maintenance and operating costs, technical risks, and the requirement for scarce technical skills. This new business model based on the PSS concept has shown a potential in overcoming some major hurdles that have hindered the progress of RFID across industrial applications.

However, RFID products, both hardware devices and software systems, have not yet been designed and developed for suitable deployment within a PSS business model. In order to tackle this key challenge, research and development efforts have been carried out to develop RFID-enabled gateway solutions that are suitable for a PSS business model [8]. RFID gateway solutions include 1) gateway hardware, and 2) gateway services. A RFID gateway hardware hub acts as a server that hosts and connects RFID-enabled devices, called smart objects, in a standard way. The gateway hub also provides a suite of software services for managing operations and events of smart objects. A significant contribution of RFID gateway technology is to provide services that capture real-time data and convert them into useful and usable real-time information for upper level enterprise application systems.

In a PSS framework, the gateway hub is the core product around which associated software services are deployed to form a product service system. Gateway hub products can be deployed in application environments just as photocopier products are rented or deployed in office applications. Technical support and services can be centrally provided to ensure that smart objects and gateways are in proper working order. Common services for RFID device management such as definition, configuration, and execution can then be operated by a central service provider and shared among different enterprise users of RFID technology.

While the gateway technology provides a technical solution to introduce the PSS concept for RFID adoption, business issues are still open for further investigation and experimentation. The revenue model among stakeholders is unclear. For example, how RFID device manufacturers collect their revenues is not clear in the PSS framework, e.g., through equipment rentals or the number of tag interrogations. A similar challenge exists on how RFID service producers will collect their revenues, e.g., through subscription or the volume of real-time information transactions. These issues must be fully addressed before the PSS approach takes effect in real-life industrial deployment.

In a different light to PSS, but in a similar paradigmatic shift, is the movement away from middleware-based applications to cloud computing-based applications for end users. Middleware can be considered computer software that connects multiple applications together. Middleware-based RFID applications were the first generation. They were usually situated in a server, processing data emanating from "dumb" readers with little processing power to translate them into a comprehensible business event. But now, the entire data processing has shifted to edgeware and cloud computing. Edgeware-based applications, also known as edge of the network applications, are typically in mobile data collecting nodes. In the case of RFID, these are mainly readers. Larger data management by means of edgeware is becoming increasingly common due to higher processing power and higher memory capabilities in the readers. The data generated by the tags are gathered by the readers and managed by edgewarebased applications. The resulting output from the edgeware 
is then transported to the cloud (or a remote server sitting in the internet), where it is further processed in accordance with the end-user requirements. Cloud computing is that operational setup where information and communication technology (ICT) is consumed as a service (e.g., software, platform, and infrastructure). The future innovations in RFID are going to be in rich tags. As both readers and tags are becoming smarter, the edge is becoming smarter. Subsequent generations will have embedded information about themselves that they can selectively and intelligently communicate with other objects in their wireless neighborhood. This would essentially form what Gadh termed as the wireless "internet of artifacts" [9].

\section{THE VISION}

RFID is often seen as the enabler of a new paradigm for computing whereby users employ information services through direct interaction with natural objects and manufactured artifacts, places and, when appropriate, living entities [10]. RFID effectively implements a transparent binding of such entities in the physical world to their info-simulacrum and vice versa, and through this link creates the opportunity for new types of systems. A core ingredient for the delivery of this vision is the availability of a comprehensive universal system of automatic identification for all tagged physical entities. Such a system would implement a fully automated data capture and maintenance of contextual, usage, and other metadata at planetary scale [11].

Moreover, such a system will have to accommodate those features of modern RFID that have made possible its current functionality, namely, the fact that practically all modern widely available passive ultra-high-frequency (UHF) RFID tags have very low storage capacity and support only simple logic in order to minimize power consumption. As a consequence, building complete and useful RFID-based systems requires that the majority of processing and storage be offloaded to surrogate services on the internet [12]. Emerging consensus seems to indicate that to support RFID systems several kinds of network services would have to be provided, specifically resolution services that link unique identifiers from diverse schemes and their metadata, and repository services that maintain and publish data related to individual identifiers. Both services should be widely accessible and available across the globe to reflect the globalized movement of manufactured artifacts typical in modern commerce.

The scale and complexity of these services both in terms of geographic scope and number of stakeholders involved is unprecedented [13]. The only system sharing its properties is the internet, which also provides a model (and the underlying infrastructure) for the provision of these services. However, the specific needs of RFID are not restricted to the transfer of data only but most importantly extend to the capture, management, and publication of persistent metadata with each element of this chain, setting its particular challenges and imposing further constraints (e.g., analytical and reporting mechanisms of the captured data, with respect to business intelligence).

Although the requirement for the development of such networked services to support planetary scale RFID was identified over a decade ago [14], the depth and complexity of the challenges presented from a service and data management perspective have been fully recognized only in the last few years and are still only partially understood. In the following section, we will attempt to identify some of the main problems and identify future research directions adopting a data management approach. In particular, we identify the main challenges in resolution and repository systems when the scale of the system encompasses the whole planet. Note that there are complementary research questions related with the provision of global RFID services, for example, those relating to questions of service positioning and adaptation to energy consumption patterns and workloads. There is significant research activity in these areas especially in the context of cloud computing that would surely benefit RFID as well [15].

\section{THE PRESSING NEED FOR DATA MANAGEMENT}

Looking closely at RFID repositories, their role is to manage entity usage information represented as application-level event records. Such services are operated either privately by individual entity custodians or by third party service providers. Conceptually, they can be considered a particular type of loosely federated distributed database, specified through public interfaces that provide methods to record, retrieve, and modify event information.

Typically, event data are inserted in the repository by different data capture applications operating at the network edge, which would often include legacy systems. Data are consumed by a variety of applications usually located at the network core, for example, enterprise resource management, data mining, and consumer-facing applications. Conceptually, the repository services are thus rather well defined and appear to be straightforward to operate, but in practice they demand particular attention due to their very large size and potential complexity of the derivative relationships between data stored. For example, one feature that merits further consideration, as it is often the source of such complexity, is the so-called containment relationship. This technique is used to create composite entities out of constellations of individual items, which can be subsequently referenced through a single handle. These composite structures are temporally defined and support multiple levels of encapsulation. As a consequence, they may lead to considerably higher complexity of even simple queries as serials within constellations have to be traced and the respective containment relationships expanded in order to produce correct results. 
The current norm is for RFID repositories to be implemented as relational databases (RDBMSs). This is of course not unreasonable as RDBMSs have been the principle paradigm in data management since the 1970s. The success of this technology has been partly due to its "one-size-fits-all" approach that is, employing a single code base for all application domains. This has proven to be a very cost-effective solution and has enabled the use of advanced data management techniques across a variety of application areas using the same small number of systems. But when used for RFID service provision, RDBMSs may incur a very high implementation cost without offering a correspondingly high performance advantage.

RFID repositories share many common features with stream-based systems, which combine real-time and persistent data, and data warehousing, where compression and column orientation play a critical role on performance. This has forced relational databases to their limit and still represents a considerable challenge. Recent work provides evidence that specialized software can achieve a 10 - to 50-fold improvement in many of these cases [16] and we seek to achieve similar performance in this case. We anticipate that the design and development of domainspecific data store engines for the main services can become a critical element in attempting to lower the barrier of entry to planetary scale RFID for a variety of medium and smaller scale organizations and for individuals. Furthermore, making these implementations open could facilitate their adoption akin to the way Berkeley internet domain name (BIND) has facilitated the adoption of domain name system (DNS) on the internet.

RFID resolution is typically achieved by maintaining a record of the complete sequence of successive custodians of a particular entity and associated metadata, from the time of initial tagging and until its expiration. Data used for such resolution must be relayed by individual repositories which register the fact that information is held for particular entities at specific locations but should not replicate the information itself.

RFID resolution can take one of two modes, one-off and standing queries. One-off queries are executed once at preset time and return results synchronously or asynchronously. They can execute either in direct or relayed style and they are comparatively simple with the main complication the possibility of inefficient or withheld access to data by specific repository operators, which may prevent the system from achieving correctness or predictable response time.

The so-called standing queries are longer running specifications of interest in patterns of application-level events, and depend upon future situation updates from potentially new data sources. In this mode of operation, individual applications subscribe to specific queries and are notified when the conditions specified in the query are met. Typically, these queries relate to the existence of a new custodian or the presence of the entity at a specific location, both of which may imply a change in ownership or a prominent event in the entity lifetime. Complexity in standing queries is due to the involvement of multiple repositories, a potentially large number of subscribing applications to a particular query, and the complex distributed internal structure of the discovery service required for performance reasons.

Standing queries present close similarities to continuous query models of stream processing and distributed event management systems. The execution profile of a standing query often matches the following pattern: event metadata are inserted as a continuous stream and are subsequently cross checked against stored data, for example, access control credentials and policies. When specific criteria have been met, suitable notifications are delivered to all subscribed applications. To carry out these tasks, it is necessary to transform standing queries into an executable query plan, optimize the query plan or generate a set of candidate plans, and map query operations onto the particular network topology. Such queries could express complex spatial, temporal, and semantic relationships and include serial and class level patterns.

This modus operandi implies the need for an expressive language for their specification with rich language features, which at the same time allows for a high performance implementation for stream-based matching. Processors optimized for RFID are not currently available and we also expect significant efficiency gains through the implementation of different distributed event management techniques, for example, multilayer and brokernetwork architectures.

\section{FUTURE APPLICATIONS}

Enter the future possibilities for RFID that are sure to overwhelm more traditional business models; perhaps what some consider the stuff of science fiction, but tested enough to now be considered science fact [17]. The insurance industry is an excellent example of how technology has been used in innovative ways to introduce premium models that were previously considered impossible to implement. In 2006, IBM and Norwich Union in the United Kingdom teamed up and installed microchips coupled with global position system (GPS) receivers to track and monitor the driving behaviors of about 7000 cars [18]. By measuring the risk based on age, gender, and time of driving, they were able to introduce customized car insurance premiums. If you are a male, under the age of 25, and driving after 11 P.M. on a Friday night, for instance, expect to pay full fees. Adjust your travel behaviors based on certain driving curfews, and expect to pay far less on your premium. It will not be too far out before implantable solutions for humans based on RFID make it possible to monitor real-time blood alcohol levels, heart rates, temperature, and other physiological characteristics - the patents were filed in some cases two decades ago. 
Web-services-based applications will form the underbelly of pervasive computing. The building blocks of the web services domain were established when middleware became prominent in the requirement for interoperability. Middleware brought uniformity and standardization, allowed for heterogeneity of various hardware components and operating systems, and provided a set of common services to developers and end users. Today, web services sit in the internet cloud serving multiple clients but with middleware components still very much acting as the enabler. Web services together with web-enabled technologies such as sensor motes will play a pivotal role in the context of ubiquitous computing in combination with RFID technology.

The convergence of sensor capabilities in RFID tags further expands their sphere of utility in applications such as perishable products. Sensor technology is being fused into RFID such that different variables measured by sensors can also be reported by tags instead of just plain IDs. The types of sensing capabilities reported to have been fused into RFID tags include temperature, acceleration, and chemical, among others. RFID-sensor fusion can help us to monitor large scale environmental factors by networking the readers with RFID sensors spread within certain bounds. This would help us to make real-time queries about the area under observation (e.g., bushfire prone zones) and also offer results at a much higher resolution than previously attempted.

Sensor-based tags have also given rise to a new category of tags known as semipassive tags. Semipassive or batteryassisted tags are different from the conventional passive tags, whereby, a battery source is provided in the tag to power the on-board sensors. The tag has other intelligent features such as sleep mode to conserve power. Applications where sensor-based tags have been introduced include tracking fresh cut flowers, monitoring temperature of drugs, monitoring blood and organs for transplant, etc., [19].

The diffusion of RFID and mobile technologies is greatly empowering a number of sectors. Miniaturized readers and tags are being embedded into mobile phones to expand their capabilities, while advanced wireless and mobile phone technologies are also being incorporated into readers. The connectivity of mobile technology to the internet makes it a suitable domain for development of web service components. Real-time-location-based systems consist of a group of sensors or passive or active RFID tags, working in concert to track the position of objects or people of interest in regular intervals. Several techniques have been devised to utilize the capabilities of existing RFID infrastructure in predicting locations of target items in an indoor setup. Real-time location-based operations will constitute a large chunk of RFID operations. The continuous updates provided by RFID systems enable transparency, speedy operation, counterfeit prevention, and staff safety by tracking people in hazardous or sensitive work environments. This capability complements the other utilities of an RFID system in an enterprise, as many organizations have the need of continuously knowing the location of their resources inside a complex indoor setup. Some examples of these are: locating tools inside a big factory floor or locating patients inside a hospital.

Opening office doors simply by showing your hands may have been used to demonstrate the capabilities of RFID in the 1990s but entrepreneurs and some government officials are now thinking outside the box. RFID-based applications have significantly gathered momentum in the medical domain. Consider, for instance, the swallowable sensor device, patented on April 2, 2009 [20], the U.S. health bill which was put forward to Congress in July 2009 containing a national medical device registry based on a possible class II implantable device, life supporting and/or life sustaining in nature [21], and the RFID implant that can detect the H1N1 virus patented in October 2009 [22]. Once upon a time having an implantable could only be imagined for restorative purposes (e.g., heart pacemaker, cochlear implant); now we are looking for new ways in which to improve services. A study carried out by IDTechEx RFID Knowledgebase [23] predicted that the two biggest contributors to demand in RFID in the healthcare sector would be pharmaceutical tagging and asset/patient and patient tracking. With automated patient tracking, many repetitive tasks such as keeping tabs on patient records, their daily drug doses, and their movement about the hospital will be delegated to automated systems. This will also reduce the number of human errors in the tasks. Enter the concept of uberveillance, in its ultimate form an omnipresent electronic surveillance that makes it possible to embed ICT devices in the human body for a variety of applications [24].

This does not mean that we can expect all humans to be walking around with chips implanted in their bodies, well not for the present anyway. Although constantly changing, the current culture probably does not warrant this kind of pervasive monitoring and tracking. But surveys are now showing time and time again that most people do not mind this kind of ubiquitous tracking of nonliving things and animals. If the online and mobile social networking phenomenon is anything to go by, 20 to 30 years from now, RFID embedded technologies might see a full-blown uberveillance society where everyone shares microdetails about themselves and their household with their respective community of interest for the cocreation of social services, particularly pertaining to infrastructure requirements engineering. This kind of web of things and people (WOTAP) scenario will only happen if RFID is embraced within the paradigms of integration, convergence, and coexistence. The future scenario is not about RFID rendering all other auto-ID technologies obsolete, nor is it about a story of migration from one technology to the next. RFID will be about harnessing the power of the technology within a 
hybrid wireless network context, knowing all too well it is the end-point data collection mechanism, the smallest common denominator of knowledge that can be acquired (the individual unit). Consider the capabilities of RFID with sensor technology, RFID and the wireless Internet, and RFID and global positioning systems. The natural trajectory when one ponders what these new convergences may herald is nothing short of breathtaking.

\section{CONCLUSION}

But to ground ourselves in the current realities and some of the technical and nontechnical challenges that RFID still presents us with, including with respect to privacy and security issues, legal/regulatory, socioethical and economic/market issues, is to admit to the need for greater coproduction among stakeholders, especially the participation of end users from the outset of service design (i.e., cocreation). RFID is far from perfect, and a greater investment is needed by all sectors to bring about a more robust and economical technology, possibly following a
PSS model, that all acknowledge as adhering to legal, ethical, and policy-related standards [25]. Item level tracking, for instance, comes with its own endowed advantages and benefits for some organizations within a retail supply chain context but may not be desirable for other application areas. A level of harmonization needs to be reached between the level of required visibility in a given service and adhering to a consumer's right to informational privacy [26]. Solutions can be devised and built-in to the design of a service to overcome such challenges; they just need to be innovative. If a consumer perceives that the value proposition to them of using a given technology outweighs any costs they may experience, then they are likely to adopt the technology. By including consumers early in the process of cocreation and coproduction of RFID technology, more innovative services are destined to come to fruition. The challenge ahead will be in harnessing planetary scale RFID services using nontraditional business models like those presented in this paper that provide us with an unforeseen level of uberveillance management and decision support.

\section{REFERENCES}

[1] K. Michael and M. G. Michael, Innovative Automatic Identification and Location Based Services: From Bar Codes to Chip Implants. Hershey, PA: IGI Global, 2009.

[2] D. L. Brock. (2001, Jan.). The Electronic Product Code (EPC): A Naming Scheme for Physical Objects, Auto-ID Center. [Online]. Available: http://www.autoidlabs.org/ uploads/media/MIT-AUTOID-WH-002.pdf

[3] International Telecommunication Union (ITU). (2005). The Internet of Things, Genf, Switzerland, ITU Rep. [Online]. Available: http://www.itu.int/osg/spu/ publications/internetofthings/ InternetofThings_summary.pdf

[4] E. Fleisch. (2010, Jan.). What is the Internet of Things? An Economic Perspective, Auto-ID Labs. [Online]. Available: http:// www.autoidlabs.org/uploads/media/ AUTOIDLABS-WP-BIZAPP-53.pdf

[5] C. E. Helfat, S. Finkelstein, W. Mitchell, M. A. Peteraf, H. Singh, D. J. Teece, and S. G. Winter, Dynamic Capabilities: Understanding Strategic Change in Organizations. Oxford, U.K.: Blackwell, 2007.

[6] S. L. Vargo and M. A. Akaka, "Servicedominant logic as a foundation for service science: Clarifications," Service Sci., vol. 1, no. 1, pp. 32-41, 2009.

[7] T. S. Baines, H. W. Lightfoot, S. Evans, A. Neely, R. Greenough, J. Peppard et al., "State-of-the-art in product-service systems," Proc. IMechE B, J. Eng. Manuf., vol. 221, pp. 1543-1552, DOI: $10.1243 / 09544054 J E M 858$.

[8] T. Qu, G. Q. Huang, Y. F. Zhang, and H. D. Yang, "Analytical target cascading for optimal configuration of production service systems," in Proc. Conf. Artif. Intell. Cogn. Sci., 2009, vol. 66, pp. 1627-1646.

[9] R. Gadh, "RFID: Getting from mandates to a wireless internet of artifacts," Comput. World: Wireless Views, Oct. 2004.
[10] G. Roussos and V. Kostakos, "RFID in pervasive computing: State-of-the-art and outlook," Pervasive Mobile Comput., pp. 110-131, 2009.

[11] E. Welbourne, L. Battle, G. Cole, K. Gould, K. Rector, S. Raymer, M. Balazinska, and G. Borriello, "Building the internet of things using RFID," IEEE Internet Comput., vol. 13, no. 3, pp. 48-55, 2009.

[12] G. Roussos, S. S. Duri, and C. W. Thompson, "RFID meets the Internet," IEEE Internet Comput., vol. 13, no. 10, pp. 11-13, 2009.

[13] G. Roussos, Networked RFID: Systems, Software and Services. London, U.K. Springer-Verlag, 2008.

[14] S. S. Chawathe, V. Krishnamurthy, S. Ramachandran, and S. Sarma, "Managing RFID data," Very Large Data Bases, pp. 118-119, 2004.

[15] A. Bavier, M. Bowman, B. Chun, D. Culler, S. Karlin, S. Muir, L. Peterson et al., "Operating system support for planetary-scale network services," in Proc. 1st Symp. Networked Syst. Design Implement., Berkeley, CA, 2004, vol. 1, pp. 253-266.

[16] M. Stonebraker, S. Madden, D. J. Abadi, S. Harizopoulos, N. Hachem, and P. Helland, "The end of an architectural era (it's time for a complete rewrite)," in Proc. Very Large Data Bases, 2007, pp. 1150-1160.

[17] M. Roberti. (2008). Two visions of an RFID-enabled future. RFID J. [Online]. Available: http://www.rfidjournal.com/ article/view/3899

[18] K. Michael, A. McNamee, and M. G. Michael, "The emerging ethics of humancentric GPS tracking and monitoring," in Proc. Int. Conf. Mobile Business, Copenhagen, Denmark, Jul. 2006, pp. 34-41.

[19] M. Roberti. (2006). Sensing new RFID opportunities. RFID J. [Online]. Available: http://www.rfidjournal.com/article/ articleview/2081/

[20] M. R. Arneson, W. R. Bandy, R. A. Davenport, K. J. Powell, and M. C. Sloan. (2009, Apr. 2).
System and Method for Manufacturing a Swallowable Sensor Device, U.S. Patent and Trademark Office. [Online]. Available: http:// appft.uspto.gov/netacgi/nph-Parser? Sect $1=$ PTO2 $\&$ Sect $2=$ HITOFF $\& p=1 \& u=$ \%2Fnetahtml\%2FPTO\%2Fsearch-bool. $\mathrm{html} \& \mathrm{r}=1 \& \mathrm{f}=\mathrm{G} \& \mathrm{l}=50 \& \mathrm{co} 1=$ AND\&d$=$ PG01\&s1 $=20090088618 \& O S=$ 20090088618\&RS $=20090088618$

[21] 111th Congress, Session 1, A Bill, To Provide Affordable, Quality Health Care for All Americans and Reduce the Growth in Health Care Spending, and for Other Purposes, U.S. House of Representatives, 2009, pp. 1001-1008. [Online]. Available: http://waysandmeans.house.gov/media/ pdf/111/AAHCA09001xml.pdf

[22] Verichip Corp, VeriChip Corporation to Present Its Glucose-Sensing RFID Microchip and Virus Triage Detection System for the H1N1 Virus at ID World International Congress, the World's Premier Event on Identification Technology, October 2009. [Online]. Available: http:// www.verichipcorp.com/pressreleases/ 102909.html

[23] P. Harrop, R. Das, and G. Holland, "RFID for healthcare and pharmaceuticals 2009-2019," in Proc. IDTechEx, 2009.

[24] M. G. Michael and K. Michael, "Uberveillance," in Macquarie Dictionary (Australia's National Dictionary), S. Butler, Ed. 5th ed., Sydney, Australia: Sydney Univ. Press, 2009, p. 1094.

[25] Future of Identity in the Information Society (FIDIS), Supported by the European Union under the 6th Framework Programme for Research and Technological Development within the Information Society Technologies (IST) Priority, 2009. [Online]. Available: http:// www.fidis.net

[26] B. D. Renegar and K. Michael, "The privacy-value-control harmonization for RFID adoption in retail," IBM $J$. Res. Develop., vol. 53, no. 2, pp. 8:1-8:14, 2009. 


\section{ABOUT THE AUTHORS}

Katina Michael (Senior Member, IEEE) received the B.I.T. degree in information technology from the School of Mathematical and Computing Science, University of Technology, Sydney, N.S.W., Australia, in 1996, the Doctor of Philosophy degree in information and communication technology (ICT) from the Faculty of Informatics, University of Wollongong, Wollongong, N.S.W., Australia, in 2003, and the Master of Transnational Crime Prevention degree from the Faculty of Law, University of Wollongong, in 2009.

Currently, she is an Associate Professor at the School of Information Systems and Technology, university of Wollongong (2002-2010), and has previously been employed as a Senior Network Engineer at Nortel Networks (1996-2001). She has also worked as a Systems Analyst at Andersen Consulting and OTIS Elevator Company. She has published several edited books, but more recently coauthored a 500 page reference volume: Innovative Automatic Identification and Location Based Services: from Bar Codes to Chip Implants (Hershey, PA: IGI, 2009). She has published over 85 peer-reviewed papers. She researches predominantly in the area of emerging technologies, and has secondary interests in technologies used for national security and their corresponding social implications.

George Roussos (Member, IEEE) received the B.S. degree in mathematics from the University of Athens, Athens, Greece, the M.S. degree in numerical analysis and computing from the University of Manchester Institute of Science and Technology, Manchester, U.K., and the Doctor of Philosophy degree from the Imperial College of Science Technology and Medicine, University of London, London, U.K.

Before joining Birkbeck College, University of

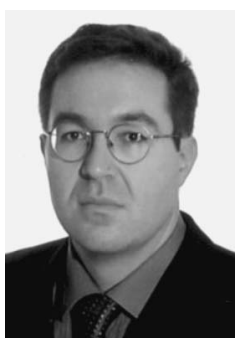
London, as a Lecturer he worked as the Research and Development Manager for a multinational information technology corporation in Athens, Greece, where he was responsible for the strategic development of new IT products in the areas of knowledge management and mobile internet; as an Internet Security Officer for the Ministry of Defense, Athens, Greece, where he designed the Hellenic armed forces internet exchange and domain name systems; and as a Research Fellow for Imperial College, London, U.K., where he conducted research in distributed systems. He is currently investigating the effects of social activity on system architectures, and exploring mechanisms to support navigation and findability.

Dr. Roussos is a member of the Association for Computing Machinery (ACM), SIGMOBILE, the IEEE Communications Society, and the IEEE Computer Society.

George Q. Huang received the B.Eng. degree in manufacturing automation from Southeast University, Nanjing, China, in 1983 and the Doctor of Philosophy degree in mechanical engineering from Cardiff University, Cardiff, U.K., in 1991.

Currently, he is a Professor at the Department of Industrial and Manufacturing Systems Engineering, The University of Hong Kong, Hong Kong. He has been previously employed as Research Fellow and Lecturer in various universities. He has

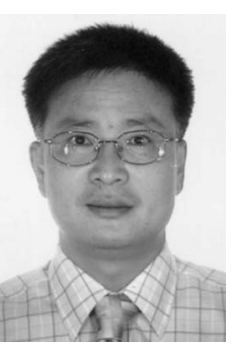
been conducting research projects in intelligent product design and manufacturing in a context of supply chain logistics. He has published over 250 research papers, half of which have appeared in reputable journals in addition to two monographs and two edited reference books.

Dr. Huang serves on editorial boards of a number of international journals. He is a Chartered Engineer and a member of the American
Society of Mechanical Engineers (ASME), the Institution of Industrial Engineers (IIE), the Institution of Engineering and Technology (IET), Hong Kong Institution of Engineers (HKIE), and Hong Kong Logistics Association (HKLA).

Arunabh Chattopadhyay received the B.S. degree from Jamia Millia Islamia (JMI) University, Delhi, India, in 2005 and the M.S. degree in electrical engineering from the Indian Institute of Technology, Kanpur, India, in 2007. Currently, he is working towards the Ph.D. degree at the Wireless Internet for the Mobile Enterprise Consortium (WINMEC) Center, University of California Los Angeles, Los Angeles.

His areas of interests are in RFID and distrib-

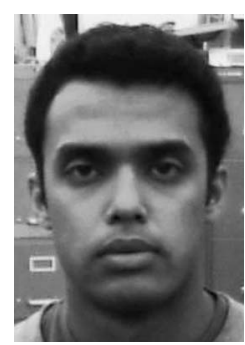
uted database systems.

Rajit Gadh (Member, IEEE) received the B.S. degree from Indian Institute of Technology, Kanpur, India, the M.S. degree from Cornell University, Ithaca, NY, and the Ph.D. degree from Carnegie Mellon University (CMU), Pittsburgh, PA.

$\mathrm{He}$ is a Professor of Engineering, Director of Wireless Internet for the Mobile Enterprise Consortium (WINMEC) Center, University of California Los Angeles (UCLA-WINMEC), and Director of UCLA Smart Grid Energy Research Center. He has

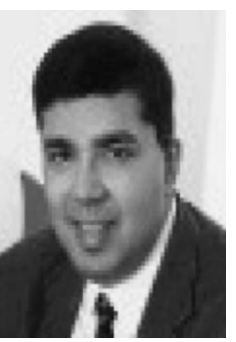
taught as a Visiting Researcher at the University of California Berkeley, has been an Assistant, Associate, and Full Professor at the University of Wisconsin-Madison, and did his sabbatical as a Visiting Researcher at Stanford University, Stanford, CA, for a year. He has lectured and given keynote addresses worldwide.

Dr. Gadh has won several awards from the National Science Foundation (CAREER award, Research Initiation Award, NSF-Lucent Industry Ecology Award, GOAL-I award), The Society of Automotive Engineers (Ralph Teetor award), IEEE (second best student-paper, WTS), the American Society of Mechanical Engineers (Kodak Best Technical Paper award), AT\&T (Industrial Ecology Fellow Award), Engineering Education Foundation (Research Initiation Award), William Wong Fellowship award from the University of Hong Kong, and other accolades in his career. He is on the Editorial board of the ACM Computers in Entertainment and the CAD Journal.

\section{B. S. Prahbu received the Doctor of Philosophy} degree.

Currently, he is a Senior Research Engineer at the Wireless Media Lab and Wireless Internet for Mobile Enterprise Consortium (WINMEC), Henry Samueli School of Engineering, University of California Los Angeles (UCLA). He is currently engaged in research in the areas of adopting wireless technologies (RFID, Wi-Fi, Bluetooth, GPRS, GPS) for enterprise applications. His areas

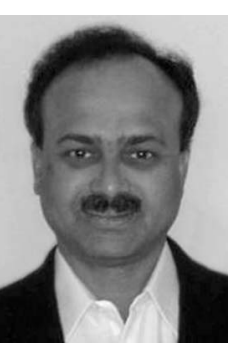
of interest include RFID ecosystem for manufacturing, development of a generic wireless sensor interface, RFID and sensors in healthcare (both in-patient and ambulatory), and semantics-based automated applications. He has been the lead architect of a RFID middleware project, a pioneering effort in developing a comprehensive RFID architecture which supports multiple RFID technologies to work synergistically to provide best-of-breed solutions to many industry verticals. He has over 30 research publications in peer-reviewed journals, conferences, and books. 
Peter Chu received the B.S. degree from the National Taiwan University, Tainan, Taiwan, in 1990 and the Doctor of Philosophy degree from the University of Wisconsin-Madison in 2001.

Currently, he is a Senior Researcher at the Henry Samueli School of Engineering and Applied Science, University of California Los Angeles (UCLA). He is a seasoned Research Manager who has supervised and steered multiple industry and academia research projects in the field of smart

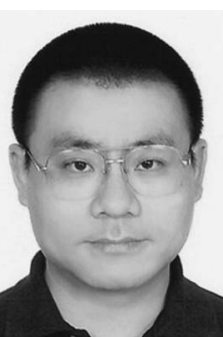

grid, RFID technologies, mobile communication (WiFi, Bluetooth, Zigbee, GPRS, 3G), media entertainment (DRM, mobile music, video, imaging, gaming, etc.), 3-D/2-D visualization of scientific data (astronomical, power system, industry process data, etc.), and computer-aided design.
He has over ten years of experience in research and development of software architectures, frameworks, and solutions, and has delivered multiple project solutions and software packages to the industry globally. He leads active research collaborative projects with companies such as Siemems, Qualcomm, Motorola, HP, Raytheon, Maersk, and Northrop Grumman. He holds two patents and has published more than 30 papers in professional engineering and scientific journals, books, and conference proceedings. He had published papers focused on RFID research and more recently was invited to author a book chapter on "Mobile, wireless and sensor networks: Technology, applications and future directions" (Wiley). He has been invited to Korea and Taiwan to speak on the current status of RFID and sensor network applications.

Dr. Chu received the Best Paper Award in Excellence for Applied Research at the 2004 Wireless Telecommunications Symposium. 